\title{
Preparing Astronomy Majors for the Job Market of the New Millennium
}

\author{
Victor Migenes \\ Department of Astronomy, University of Guanajuato, \\ Apdo Postal 144, Guanajuato, GTO, \\ CP 36000, Mexico \\ vmigenes@astro.ugto.mx
}

Received 1999 September 1, accepted 2000 April 14

\begin{abstract}
In the past few years the American Physical Society (APS) has conducted a number of surveys among the graduate student population in the US and also among young researchers. The purpose was to get an idea of the career expectations of the students and how these are met later on in their life. Two of the conclusions were: (1) students want to work in a research environment, preferably academic, and (2) graduate and undergraduate programs are not preparing them well for the different challenges and goals found in industry, the private sector and national laboratories. Jobs in academia, especially tenured positions, have been difficult to obtain forcing many students to give up on their goals after one or two postdoctoral positions. Some have found jobs in other sectors but others feel frustrated that their careers have not met their expectations and are poorly 'prepared' for other options. In the areas of Physics and Astronomy there is not much of a job market without graduate studies. So most students must continue graduate work, in these or other fields, in order to compete well in the job market. Graduate and undergraduate programs must become more responsible for the present state of affairs and for implementing improvements. This can be done by broadening the scope of the present programs so that a student is better prepared to face the challenges of other job opportunities. We present here a BSc program designed by astronomers and physicists, at the University of Guanajuato, to try to address some of these concerns and better prepare the students for either continuing with graduate studies or finding employment in an ever-changing job market.
\end{abstract}

Keywords: astronomy education—astronomy employment

\section{The Problem}

For the past 10 years the problems of the job market for physicists and astronomers have been discussed from the perspective of students entering a university program, students about to graduate and from those that have been working in the field for some time. The publications of the American Physics Society (APS), the American Institute of Physics (AIP) and the American Astronomical Society (AAS) have been the forum for such discussion. In most workplaces, especially in academia and national laboratories, budget cuts have lead to downsizing, not filling openings caused by retirees, and/ or hiring personnel on short term positions which are usually supported by 'soft' monies (postdocs, research professors, research associates, etc).

The 'crisis' in the Physics job market (which includes Astronomy), specifically in the US, has been studied closely in the past 10 years (Cioffi 1995a; Mulvey \& Neuschatz 1996; Kumagai 1997, 1998; AIP 1997a, 1997b, 1998, 1999a, 1999b). Having worked as a professional astronomer in various countries it is clear to me that the same situation and circumstances can be found, to a greater or lesser extent, outside the US. The depressed job market is equally bad for Science Majors (BSc) and the $\mathrm{PhD}$ populations, perhaps worse so for PhDs since the majority of BScs choose to continue graduate school in Physics or in some other fields (see diagram on page 52 of AIP 1997b). With the number of postdoctorals being twice as high as the number of new $\mathrm{PhDs}$ produced each year, it is likely that the number of experienced postdoctorals re-entering the postdoctoral market far exceeds those entering for the first time. These populations also compete in the job market with more experienced PhDs who exit industry or the federal goverment as funding for basic and applied research diminishes. The authors of the survey determined that $50 \%$ of those who answered the survey, desire positions in academia and from these $20 \%$ will eventually get permanent academic positions in the USA. More surprisingly, $57 \%$ of those with jobs indicated that they had accepted positions where they would make very little use of their physics background.

On another front, the poor prospects of the job market is one of the causes for a continuous drop in Physics enrollment in undergraduate and graduate programs, through most of the 1990s (Cioffi 1995b; Mulvey \& Neuschatz 1995, 1996; AIP 1997a). Though the numbers of new BSc and $\mathrm{PhD}$ recipients has risen, a drop is expected soon if the enrollment trend continues. Physics and Astronomy degree recipients are also taking about one year longer, on the average, to graduate compared with students from previous classes.

Another unpleasant fact is that since the 1950s the median age of physics professors in the US universities has been rising almost linearly (Gruner et al. 1995), such that by $1992,50 \%$ of the full professors were at least 54 years old. Over the same period of time, the distribution of physics subfields, in academically employed PhDs, has remained roughly the same. Though the first point shows that the academic job market has been narrowing 
over the past two decades, I find the second point more disturbing because it seems to indicate that physics research (and probably education) has 'evolved' to encompass a fixed set of subjects and areas of specialization, and one consequence is the loss of job opportunities in new areas of research. In the past few years we have seen more interesting and exciting developments of cross-fertilisation with biology, medicine, complex systems, advanced materials, earth sciences and information systems, to name but a few. Still, the few who are working in these areas are not yet having an impact within US physics departments or must leave the academic environment to work in industry.

This is, essentially, the current state of the undergraduate and graduate programs in the US and the corresponding job markets. Though much more can certainly be said and argued in this subject, this is not the purpose or scope of this paper. The 'state of affairs' is serious enough no matter what the cause(s) or other effects might be. Most experts studying the job market attribute the problems not only to the 'state of the economy worldwide and local' or the lack of strong research initiatives and the budgets required, but also to the poor preparation students are receiving in order to either: (a) pursue studies in other related or non-related fields which may provide better job opportunities, or (b) get jobs in other related or non-related fields (Cioffi 1995c). Wolf (1994) has discussed, among other issues, how poorly physicists are being trained to work successfully in non-academic fields. The needs in the academic and industrial work-places are very different. Perspectives and constraints like: time pressure, budgets, team work, manufacturability, etc., define this highly competitive working environment. The engineers' academic training is more suited for this work-place. A few programs have been developed especially for undergraduate students in physics, chemistry, mathematics or engineering in order to expose them to large-scale projects that involve team work among people from different disciplines and the research needs of other fields. For example, the program at the University of California's Davis campus in collaboration with Livermore Laboratories trains students in 'applied physics' with a strong industry perspective. The general idea is that if students get involved in research, outside the academic setting, they will be more prepared to face the challenges in other career opportunities. It seems that these efforts have worked for the few exposed to this training. In Carthage College, Wisconsin, their program is designed to supplement formal science training with the concepts and skills required in the financial, economic and business fields. US universities are starting to involve industry in the training of BSc students by designing work and study programs in which students can get some 'on the job training' and experience, for a few summers or semesters, and see what industry is all about. This experience has proven valuable in getting them their first job (Cioffi 1995a; Kumagai 1999a).

The Society of Physics Students (SPS), a national association for mostly BSc students in the US, and the AIP have been emphasising the message to produce more 'flexible' students. The new motto for BSc students is 'Study physics to be a non-physicist'. On the other hand, much reform is being discussed for the graduate programs, as illustrated by the document released by a joint committee of the National Academy of Sciences, the National Academy of Engineers and the Institute of Medicine (Griffiths 1994). The main recommendation is to broaden the range of academic options to turn out more versatile graduates. The most compelling point (Gruner et al. 1995) is that physics employment is dependent upon social needs that must be fulfilled by scientists that have been prepared properly to address them. Social needs and concerns have changed and will continue to do so, hence present and future generations of scientists must be well prepared to meet the new challenges. While changes to graduate programs have been slow, much discussion has been focused on making the $\mathrm{PhD}$ degree more 'practical'. A more immediate approach has been to modify the MSc degrees in Science and Mathematics to comply with the needs of an emerging or interdisciplinary field (Kumagai 1999b). More than 50 new 'professional' MSc degree programs now exist in areas like biotechnology, financial mathematics, environmental sciences, etc., which intend to prepare the student for careers outside academia (managing industrial research projects, working as liaison between R\&D and business, etc.). A job market is rapidly growing for these 'professional' MSc degrees which prepares students to become research managers in industry, national laboratories and goverment agencies.

As an update of the job market's state of employment it should be mentioned that the employment opportunities for new $\mathrm{PhDs}$ in physics have marginally improved in the last three years (Kumagai 1998, 1999a, 1999 b), partly due to a stronger economy but mostly because many are finding jobs in other fields such as engineering, computer programmers, financial analysts, etc. The job market for PhDs, with degrees obtained before 1994, has also improved within the academic environment as results of a more recent survey show (AIP 1999a, 1999b).

\section{Our Contribution to Search for a Viable Solution}

So far, I have only discussed the pertinent aspects of the problem which have led to the development of our new undergraduate program in physics, astrophysics and physics engineering. This proposal will not solve all the problems but I do believe it shows a way in which we can address some of them. The aim of our new BSc program is to improve and increase the skills offered by more 'classical' programs in order to improve the 
employment opportunities of the students and also their chances of success and flexibility in graduate school. According to a survey conducted by the AIP in 1994 the skills most frequently used by physics degree holders are (AIP 1995) (listed in order of importance):

- for BScs employed in industry, governmment and national laboratories; problem solving, good interpersonal relations, advanced computer and management skills are required, followed by business principles, technical writing and advanced mathematics skills

- for PhDs in the academic environment; problem solving, technical writing, good interpersonal relations, knowledge of physics and advanced mathematics are required, followed by knowledge of specialised equipment and statistical concepts.

From the survey results two conclusions are: (a) BSc recipients have virtually no job opportunities in academia and (b) knowledge of physics, advanced mathematics and statistics are not considered as very important skills within the job opportunities available. The main skill required for both populations is problem solving which is mostly learned in the study of experimental methods. Feynman (1985) once strongly criticised Brazilian academics, in 1951, that no science was being taught in Brazil. His opinion was based on the lack of experimental experience in their programs and practical applications for what was being taught. Undergraduate and graduate programs must expose their students to more and better laboratory experience which is one of the aims of our program.

\section{In Mexico}

The situation in Mexico is a very peculiar one relative to the rest of Latin America. The economies of Mexico and Brazil are among the most stable in the region, and both have a strong interest in promoting and supporting science and technology education and the job market (Macilwain 1999). Both governments have been spending hundreds of millions of dollars a year in R\&D, improving undergraduate and graduate programs, and developing national laboratories and institutes where students can gain the experience needed and/or promoting international collaborations between universities and big projects abroad.

In Mexico, most graduate programs in Physics stress more the theoretical than experimental research, primarily due to the high costs of establishing laboratories, but this has been changing in the past few years. The job market for research in sciences and engineering is growing very rapidly in Mexico. Many of Mexico's PhDs in Physics and Astronomy have earned their degrees in the US and/or Europe with grants provided by the Mexican government. This has worked out very well because most of those students return with new ideas, perspectives and collaborators. One big problem is that the students graduating from high school (year
12) have a lower education level compared to that in the US, Europe and Australia, especially in sciences. Most university science and engineering programs must offer remedial courses over the summer, or for the first semester, before students can start a regular program. These remedial programs help the students to catch-up or brush-up on subjects they should have been exposed to in high school.

To meet the growing demand for good researchers in pure and applied sciences in 1998, we designed and developed two BSc programs in Physics \& Astrophysics and Physics Engineering. The programs are 4.5 years long and have a common base of four semesters in which the students are exposed to the standard courses in Calculus, Introductory Physics, Physics Laboratories, Linear Algebra, Differential Equations, Vectorial Analysis, and Mathematical Methods for physicists. At the end of their fourth semester the students may choose the area in which they want to continue and graduate. This is the first BSc program in Astrophysics offered in Mexico, a country where it is usual for the students to graduate with a physics major and then continue astrophysics in graduate school. The Physics Engineering degree is not meant to produce an engineer with a physics specialty but to produce physicists who can work in the industrial environment, and communicate with and relate to engineers. The program is different from many others in Mexico, the US, Europe and Latin America because in addition we require:

- students to become proficient in English (a seven semester English program is part of the curriculum)

- two courses in Electronics with laboratory experience

- two courses in Computer Programming in Fortran and $\mathrm{C}$

- chemistry with laboratory in order to learn other kinds of laboratory techniques

- one year of advanced level laboratories in physics (one additional laboratory in observational techniques and instrumentation in astronomy for those interested in this major)

- the four introductory physics courses (including Modern Physics) with laboratory work

- five upper level physics courses in the 'classical' subjects

- one semester Seminar course where the student is not only expected to study specific research topics but also to prepare and present reports on assigned topics

- students to participate in some research project and submit a mini-thesis which is evaluated by a committee

- courses in project management and planning, etc. (for the physics engineering majors).

The course work of the first three semesters of the program is common with those in other engineering degrees (same courses in physics, mathematics and 
computation), in the university, allowing the student to make his/her choice of major or change his/her specialty without losing the time invested.

In addition, we are planning to get Mexican industry involved in a work-study program in which the students can gain valuable experience in a 'real' working environment. We will provide counseling on job opportunities and careers for the students as they start looking for employment. The program has been running for only three semesters and it will be at least four years before we can tell if it is successful in providing the additional tools that potential employers are looking for. For those students who will continue with graduate studies we expect that they will be better prepared to meet the challenges they will find and to be more productive in the research projects/groups they join.

How about those students who desire to enter other graduate programs or pursue more 'classical' careers? This should not be a problem. We do not expect that students working in this new program will have problems trying to meet the challenges of the present system, like the Graduate Record Examination (GRE). This exam, a requisite for entering any physics and/or astronomy program in the US, tries to measure the student's knowledge of theoretical physics acquired through 'classical' programs. Essentially, from the physics intermediate level courses or 'core' courses which are: Classical Mechanics, Electromagnetism, Quantum Mechanics, Thermodaynamics, Statistical Mechanics and Mathematics. Our students will be well prepared on this subject since they are still part of the new curriculum. The changes in our program are mainly additions to improve the students 'marketable' skills. Only time will tell how well the program is addressing the issues discussed earlier. We shall monitor the students progress and success in the job market and present a report in 5-6 years.

\section{References}

AIP Education and Employment Statistics Division 1995, 'Stat of the Month', Phys. Today, 48(June), 48
AIP Education and Employment Statistics Division 1997a, 'Graduate Enrollments in Physics and Astronomy plunge', Phys. Today, 50(June), 76

AIP Education and Employment Statistics Division 1997b, 'Postgraduation Plans of the Class of 1996', Phys. Today, 51(Aug), 52

AIP Education and Employment Statistics Division 1998, 'Physics Baccalaureates: Numbers down, Salaries up', Phys. Today, 52(Nov), 54

AIP Education and Employment Statistics Division 1999a, 'Number of Physics Faculty is edging up', Phys. Today, 52(July), 48

AIP Education and Employment Statistics Division 1999b, 'Salaries rise, Unemployment falls among PhD Physicists', Phys. Today, 52(Aug), 57

Cioffi, D. F. 1995a, 'A New Program offers Expertise from Business and the Art to Science Majors', Phys. Today, 48(June), 47

Cioffi, D. F. 1995b, 'What Changes lie in Store for US Graduate Physics Education?', Phys. Today, 48(Sept), 79

Cioffi, D. F. 1995c, 'Latest AIP Survey confirms Physicists Fears', Phys. Today, 48(Oct), 56

Feynman, R. P. 1985, Surely You Are Joking, Mr Feynman! (New York: Norton)

Griffiths, P. A. 1994, 'Reshaping the Graduate Education of Scientists and Engineers', US National Academy of Sciences Report

Gruner, S. M., Langer, J. S., Nelson, P., \& Vogel, V. 1995, 'What Future will We Choose for Physics?', Phys. Today, 49(Dec), 25

Kumagai, J. 1997, 'Survey finds Tight but Volatile Academic Market', Phys. Today, 50(May), 54

Kumagai, J. 1998, 'Employment Outlook for New PhDs improves, as Other Fields hire More Physicists', Phys. Today, 51(Jan), 49

Kumagai, J. 1999a, 'How will the New Engineering Education Criteria affect Physics?', Phys. Today, 52(Jan), 59

Kumagai, J, 1999b, 'Professional Master's Degree promise Quicker Entry into Industry Jobs', Phys. Today, 52(June), 54

Macilwain, C. 1999, 'Stability offers Unique Opportunity for Research', Nature Suppl., 398, A4

Mulvey, P. J., and Neuschatz, M. 1995, 'Physics Enrollments drop for 2nd Straight Year', Phys. Today, 48(April), 76

Mulvey, P. J., and Neuschatz, M. 1996, 'Physics Enrollments continue to fall', Phys. Today, 49(May), 63

Wolf, W. P. 1994, 'Is Physics Education adapting to a Changing World'?, Phys. Today, 47(Oct), 48 